\title{
TLC and GC-MS analysis of petroleum ether fraction of fermented wood "Nikhra" of Acacia seyal
}

\author{
Noha Fadle ${ }^{1}$, Abdalbasit Adam Mariod², Hiba Abdel Rahman Ali ${ }^{3}$, Alfatih Ahmed Hasan ${ }^{4}$ \\ ${ }^{I}$ The National Centre for Research, Environment and Natural Resources Research Institute, Khartoum, Sudan. \\ ${ }^{2}$ Indigenous Knowledge Center, Ghibaish College of Science and Technology, Ghibaish, Sudan. \\ ${ }^{3}$ Commission for Biotechnology and Genetic Engineering (CGEB), National Centre for Research \\ ${ }^{4}$ Department of Organic Chemistry, College of Science, Sudan University of Science and Technology, P.O. Box, \\ Khartoum, Sudan.
}

Corresponding author: basitmariod58@gmail.com

\begin{abstract}
This study aims to detect organoleptically Acacia seyal fractions (petroleum ether, chloroform, methanol and aqueous) fermented wood "Nikhra" ofthe fractions accumulating the strongest sweet fragrance these fragrances were mainly accumulated in the petroleum ether fermented wood "Nikhra" fraction and analysis fraction by using chromatographic and spectroscopic analysis. Petroleum ether fermented wood "Nikhra" fraction analysis with TLC and spray TLC with vanillin $\mathrm{H}_{2} \mathrm{SO}_{4}$ (pink) (C1, C2,C3,C4,C5,C6,C7), Rf values (0.92, 0.86, 0.71, 0.64, 0.57, $0.50,0.36)$, were expected to be phenolic, with vanillin HCL (red) compounds spots (C5,C6,C7) with Rf values $(0.57,0.50,0.37)$ was expected to be catechin and with vanillin $\mathrm{H}_{3} \mathrm{PO}_{4}$, blue-violet zones compounds spots (C6, C7), with Rf values $(0.50,0.36)$, were expected to be lignans. Petroleum ether fermented wood"Nikhra"fraction was divided into two types of compounds classes aromatic and non-aromatic by http://research.easybib.com and hence compounds were classified to phenolics and terpenoids compounds by GC/MS. Fragrant aromatics or terpenoids were targeted in this part of study. GC-MS analysis gave a spectrum of fragrance aromatic compounds (phenolics) in the petroleum ether fermented wood "Nikhra"fractions of A.seyal, was Petadecanoic acid (5.64\%) and Tetracosamethyl-cyclododecasiloxane (4.17\%) total fragrance aromatic compounds (44.57\%), and main terponoids compounds was Octadecanoic acid (2.52) \% total fragrance aromatic compounds $(11.87 \%)$.
\end{abstract}

Keywords: Acacia seyal, Gas Chromatography (GC), Thin-layer chromatography (TLC)

\section{Introduction}

The resinous heartwood of $A$. seyaltrees are usually used in Sudanese fragrances. The wood of $A$. seyal is pale yellow to medium brown, with localized pinkish-brown patches and some dark mahogany-red heartwood in larger or older individuals. A. seyal wood has potential in rural areas as timber. A. seyal, also produces a gum which, in spite of being of an inferior quality than that of A. senegal, is still marketed in Sudan 36.000-40.000 tons. The gum is edible when fresh, with a slightly acidic taste. Talh gum is attractive because of its clarity and solubility, gum is mixed with soot and powdered Nubian sandstone for black and red ink (Kimaroet al., 2011). Phytochemically A. seyal was characterized with high contents of proteins, phenolics, flavonoids and anthocyanins. The bark contains $18-30 \%$ tannins and is a source of red dye (Orwa et al., 2012). The bark of A. seyal is the most valuable part of A. seyal. It is, extensively, used for feeding cattle, goats and sheep during the dry season. In human medicine $A$. 
seyal leaves, gum and bark are used in phytotherapy for haemorrhage, colds, diarrhoea, gastro-intestinal disorders, jaundice, biliary diseases, syphilis, and headaches and as emollient, astringent, for burns and ophtalmia (Orwa et al., 2012).

\section{Materials and Methods}

\section{Collection of plant materials}

Fermented hardwood "Nikhra"of A. seyal were collected in March 2011 from Kordofan state, Sudan. They were, carefully, washed, oven-dried for $1 \mathrm{~h}$ at $50^{\circ} \mathrm{C}$ and put in the shade in an aerated place till complete drying, then were ground into a fine powder.

\section{Plant materials preparation and extraction}

A hundred $\mathrm{g}$ of ground powder of each plant was extracted using methanol and a soxhlet apparatus. The methanolic extract was fractionated, sequentially, using solvents of increasing polarity namely petroleum ether, chloroform, and aqueous. Fractions were dried using an evaporator and stored at $4^{\circ} \mathrm{C}$ for further analysis (Fyhrquist et al., 2002).
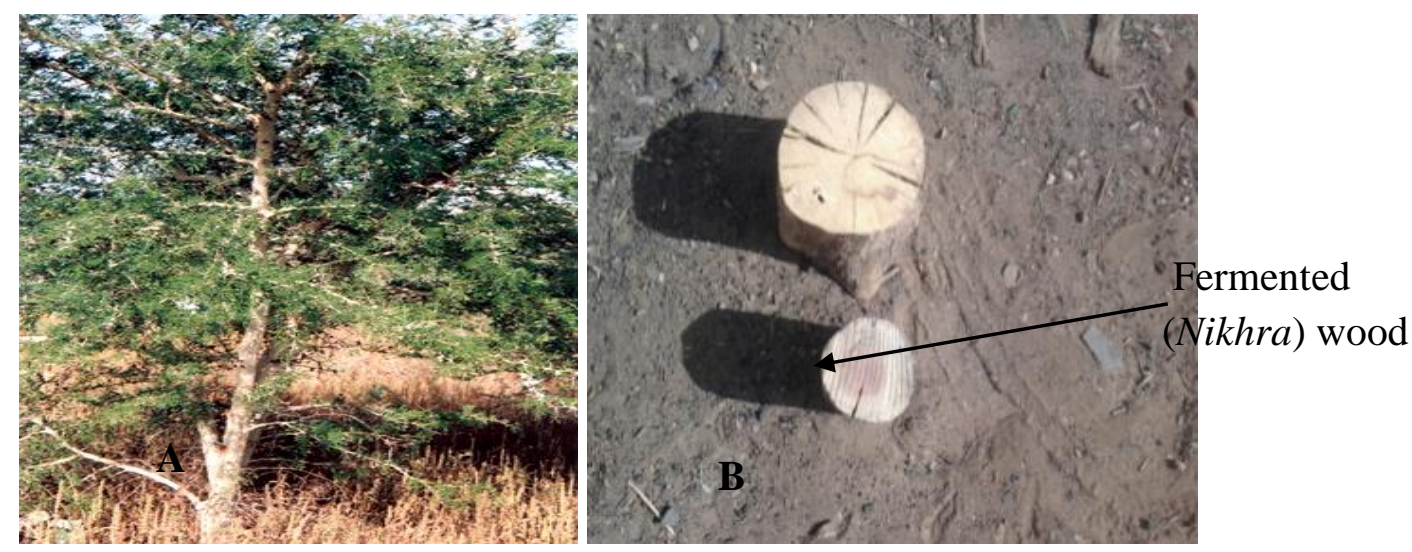

Figure 1. (A).Tree of Acacia seyal (Talh) (B). Fermented wood (Nikhra) of Acacia seya

\section{Thin layer Chromatographic analysis}

TLC was performed on a pre-coated silica gel TLC plates grade F254 (E-Merck, Darmstadt, German) to determine the number of compounds present in petroleum ether fermented wood "Nikhra" fraction.sample was spotted at $1 \mathrm{~cm}$ from the bottom ofsilica gel plates using capillary tubes. Development of the chromatogram was done in closed tanks, in which the atmosphere has been saturated with eluent vapour by wetting a filter paper lining. The chromatogram was visualized under UV light (366 nm and $254 \mathrm{~nm}$ ), Natural Product Reagent (NPR), $\mathrm{H}_{2} \mathrm{SO}_{4}, \mathrm{HCL}$ and $\mathrm{H}_{3} \mathrm{PO}_{4}$ acid reagent spray. The Rf values of the compounds were calculated using the following formula.

$\mathrm{Rf}=$ distance travelled by the compound/Distance travelled by the solvent front

\section{GC-MS Analysis}

Petroleum ether fermented wood "Nikhra" fraction was subjected to GC MS analysis to identify the various bioactive compounds present. The sample was analyzed in GCMS-QP2010 Plus from Delhi 
University (DU) India. ACQ Mode Scan: $40 \mathrm{~m} / \mathrm{z}$ to $600 \mathrm{~m} / \mathrm{z}$, Column flow is $1.21 \mathrm{~mL} / \mathrm{min}$ and total flow is $16.3 \mathrm{ml} / \mathrm{min}$. Flow control with linear velocity which $40.9 \mathrm{~cm} / \mathrm{sec}$. The identification of compounds was done using computer matching of mass spectra with those of standards (WILEY8. LIB. and NIST11.library).

\section{RESULTS AND DISCUSSION}

\section{Thin layer Chromatographic analysis}

The presence of flavonoids was confirmed by their color change from quenching fluorescence (254nm) to yellow or orange color for flavonoid and prominent blue color in case of flavonoidal acids or other phenolic acids (366 nm) after spraying with Natural Product Reagent (NPR). Polyphenols were mainly accumulated in the petroleum ether fraction has been detected using NPR. Fluorescence behavior of flavonoids in response to NPR is structure dependent. Flavonoids e.g. quercetin and myrecitin develops orange color and those of kaempferol and isorhamntin yellow to green colors. Flavones glycosides of luteolin develops orange colors and those apigenin yellow to green (Wagner and Bladt, 1996).

Vanillin $\mathrm{H}_{2} \mathrm{SO}_{4}$ is a universal reagent that detects components of the petroleum ether fraction, terpenoids, phenols etc., typical pink to purple colors were developed upon spraying with vanillin $\mathrm{H}_{2} \mathrm{SO}_{4}$ (heat $110^{\circ} \mathrm{C}$ ). All phenolic at UV $254 \mathrm{~nm}$ show prominent quenching, and they give blue fluorescence at UV $366 \mathrm{~nm}$ (Wagner and Bladt, 1996). After spraying fraction of the petroleum ether of fermented (F) wood of $A$. seyal by vanillin $\mathrm{H}_{2} \mathrm{SO}_{4}$, they showed typical pink and purple zones of phenolic. Accordingly compounds spots spots (C1, C2, C3, C4, C5, C6, C7), $\mathrm{R}_{\mathrm{f}}$ values $(0.92,0.86,0.71$, $0.64,0.57,0.50,0.36$ ), were expected to be phenolic.

Vanillin HCL is specific reagent that detects components of catechin. All catechin at UV $254 \mathrm{~nm}$ show prominent quenching, and they give blue fluorescence at UV $366 \mathrm{~nm}$ (Wagner and Bladt, 1996). After spraying fraction of the petroleum ether fraction of fermented (F) wood of A. seyal by vanillin HCL, they showed typical red zone of catechin, accordingly compounds spots (C5, C6, C7), with $\mathrm{R}_{\mathrm{f}}$ values $(0.57,0.50,0.37)$, was expected to be catechin. Lignans are formed by oxidative coupling of $\mathrm{p}$ hydroxyphenylpropeue units, often linked by an oxygen bridge. They are found in fruits, foliage, heartwood and roots. All lignans at UV $254 \mathrm{~nm}$ show prominent quenching, and they give blue fluorescence at UV $366 \mathrm{~nm}$ (Wagner and Bladt, 1996). After spraying the petroleum ether fraction of fermented (F) wood of $A$. seyal by vanillin $\mathrm{H}_{3} \mathrm{PO}_{4}$, they showed typical red to blue-violet and brown zones of lignans, accordingly compounds spots $(\mathrm{C} 6, \mathrm{C} 7)$, with $\mathrm{R} f$ values $(0.50,0.36)$, respectively were expected to be lignans.

\section{Gas chromatography mass spectrometry (GC/MS) of petroleum ether fraction.}

The chemical composition of Nikhra petroleum ether fractions of $A$. seyal was analyzed by GC/MS. The compounds identified by matching their fragmentation patterns in mass spectra with those stores in NIST library with the help of HPCHEM software published mass spectra. Petroleum ether fractions were divided into two types of compounds classes aromatic and non-aromatic and hence compounds were classified to phenolics and terpenoids compounds by GC/MS. Fragrant aromatics or terpenoids were targeted in this part of study by http://research.easybib.com.

Anjaneyulu, and Rao (2000) chemically examined the hexane extract of the roots of Excoecaria agallocha they isolated eleven diterpenoids, while Nakanishi et al. (1984) isolated fragrant sesquiterpenes as major constituents from the wood of Aquilarza malaccenszs and identified as aagarofuran, ( - )-lo-epl-y-eudesmol and oxo-agarospirol. 
In all petroleum ether fractions Area\% represent the concentrations of corresponding compound, main fragrance aromatic phenolics and terponoids compounds in the petroleum ether fractions of $A$. seyal "Nikhra" are presented in Table (1 and 2).

Table 1: Chemical composition of fragrant aromatic compounds (phenolics) in the petroleum ether fractions of A.seyal fermented wood "Nikhra".

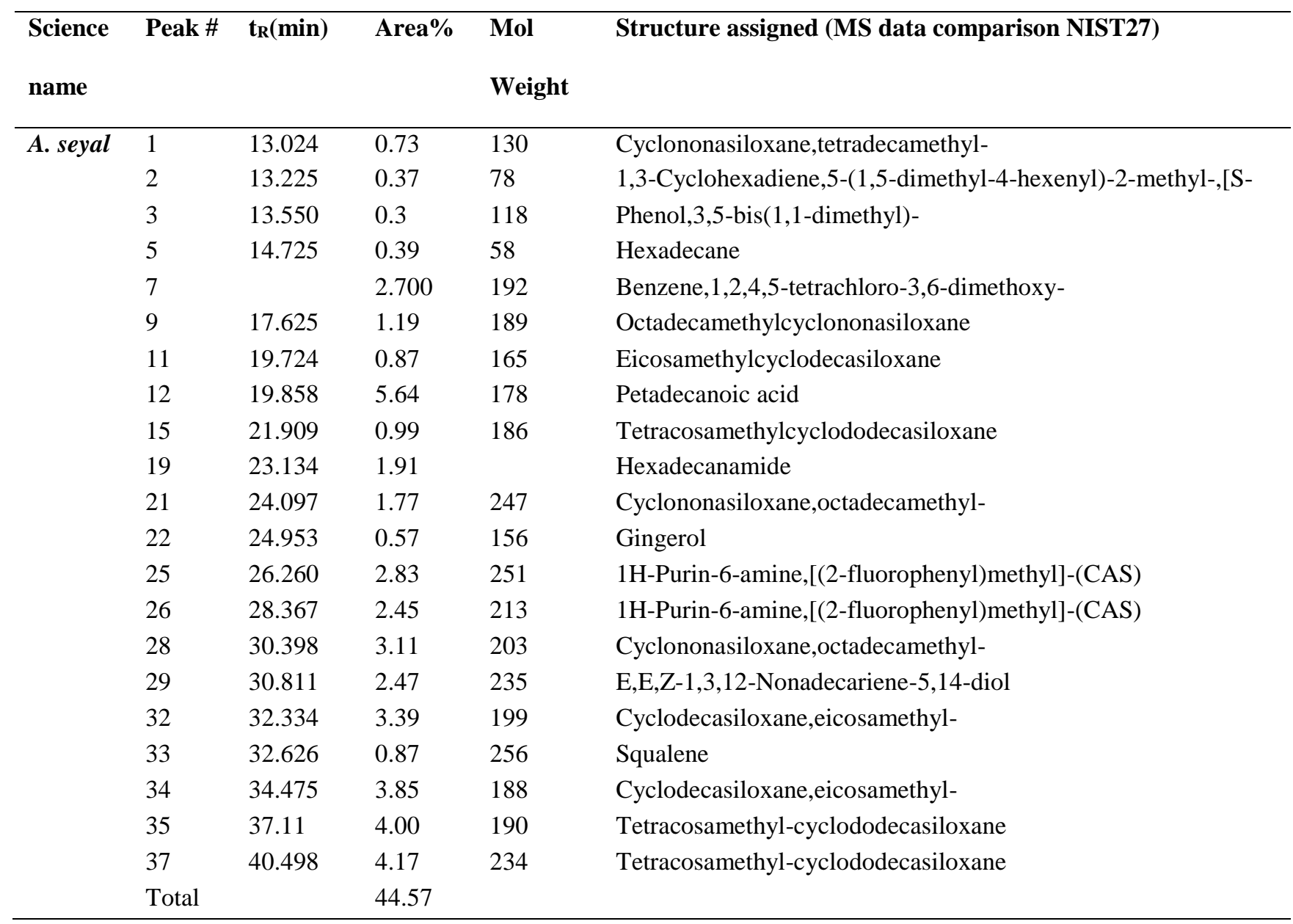


Table.2: Chemical composition of fragrant aromatic compounds (Terpenoids) in the petroleum ether fractions of A. seyal fermented wood "Nikhra".

\begin{tabular}{|c|c|c|c|c|c|c|}
\hline $\begin{array}{l}\text { Science } \\
\text { name }\end{array}$ & Peak \# & $\mathbf{t}_{\mathbf{R}}(\mathrm{min})$ & Area \% & $\begin{array}{l}\text { Mol } \\
(\mathrm{m} / \mathrm{z})\end{array}$ & Weight & $\begin{array}{l}\text { Structure assigned (MS data comparison } \\
\text { NIST27) }\end{array}$ \\
\hline \multirow[t]{16}{*}{ seyal } & 6 & 7.942 & 0.39 & 40 & & o-Xylene \\
\hline & 8 & 9.550 & 2.04 & 69 & & Alpha-pinene,(-) \\
\hline & 9 & 10.167 & 0.24 & 44 & & Camphene \\
\hline & 10 & 11.258 & 0.39 & 47 & & beta.-Phellandren \\
\hline & 13 & 13.625 & 0.23 & 43 & & dl-Limonene \\
\hline & 14 & 13.733 & 0.10 & 47 & & 1,8-Cineole \\
\hline & 21 & 31.108 & 0.10 & 49 & & Zingiberene \\
\hline & 23 & 34.183 & 0.30 & 55 & & Heptadecane \\
\hline & 24 & 35.933 & 0.25 & 74 & & methyl2-(4-methoxy-phenoxy)propanoate \\
\hline & 27 & 39.525 & 1.02 & 216 & & Octadecamethylcyclononasiloxane \\
\hline & 35 & 43.442 & 2.52 & 242 & & Octadecanoic acid \\
\hline & 36 & 43.692 & 1.82 & 213 & & Octadecanamide \\
\hline & 43 & 46.000 & 0.58 & 288 & & Eicosamethylcyclodecasiloxane \\
\hline & 44 & 46.217 & 0.47 & 184 & & Octadecanamide \\
\hline & 47 & 48.283 & 1.42 & 155 & & Tetracosamethyl-cyclododecasiloxane \\
\hline & Total & & 11.87 & & & \\
\hline
\end{tabular}

Balaban (2004) studied the tannin composition of wood of Ceratonia siliqua using GC-MS. The fractioned methanolic extracts revealed phenolic compounds (gallic acid), flavonoids (catechin), methyl inositol and chalcone. Main fragrance aromatics compounds (phenolics) in the petroleum ether fractions of A.seyal was petadecanoic acid (5.64\%) (Fig.1) and tetracosamethyl-cyclododecasiloxane (4.17\%) total fragrance aromatic compounds (44.57\%) (Table 1; Fig2), and main terponoids compounds was Octadecanoic acid (2.52) \% total fragrance aromatic compounds (11.87\%) (Table 2; Fig. 3). 


\section{$\infty$ Target $>\infty$}

Linett:12 R.Time:19.858(Scanti:1784) MassPeaks:178

RawMode-Single 19.858(1784) BasePeak:73.00(925714)

BG Mode:19.917(1791) Group 1 - Event 1

${ }^{100}$ T

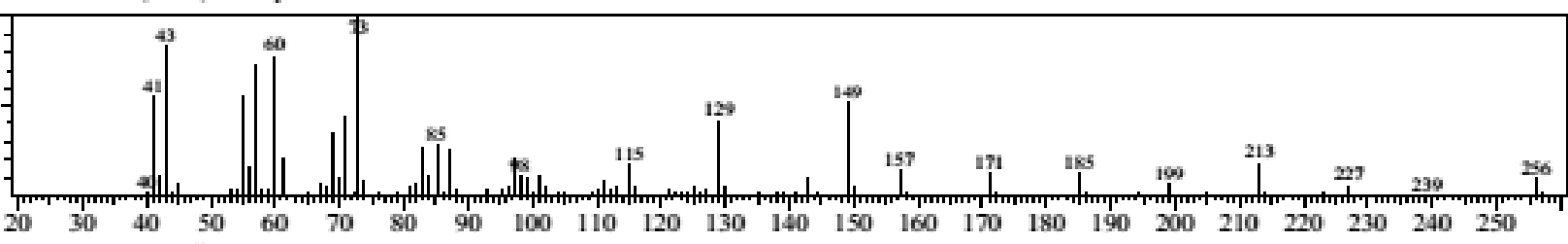

Hitit:1 Entry-20335 Library=NIST27.LIB

SI:91 Fommula:C15H30O2 CAS:1002-84-2 MolWeight:242 Retlndex:0

Compline:Pentadecanoic acid

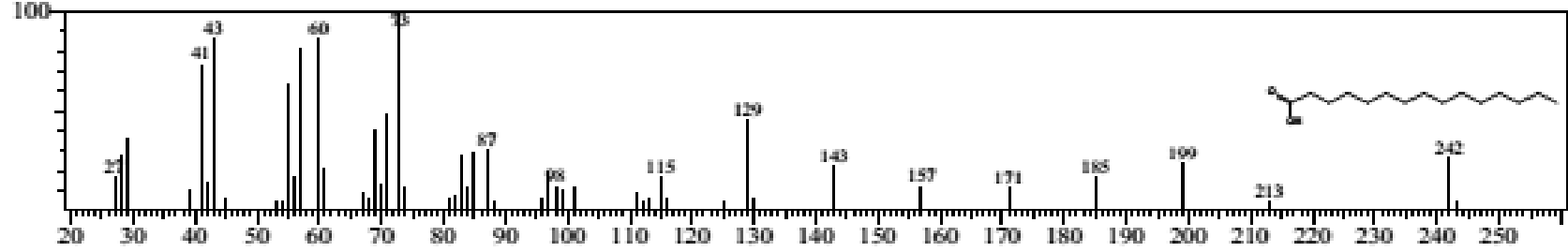

Figure 1. Fragrant aromatic compounds (phenolics) in the petroleum ether fractions of A.seyalNikhra (Petadecanoic acid).

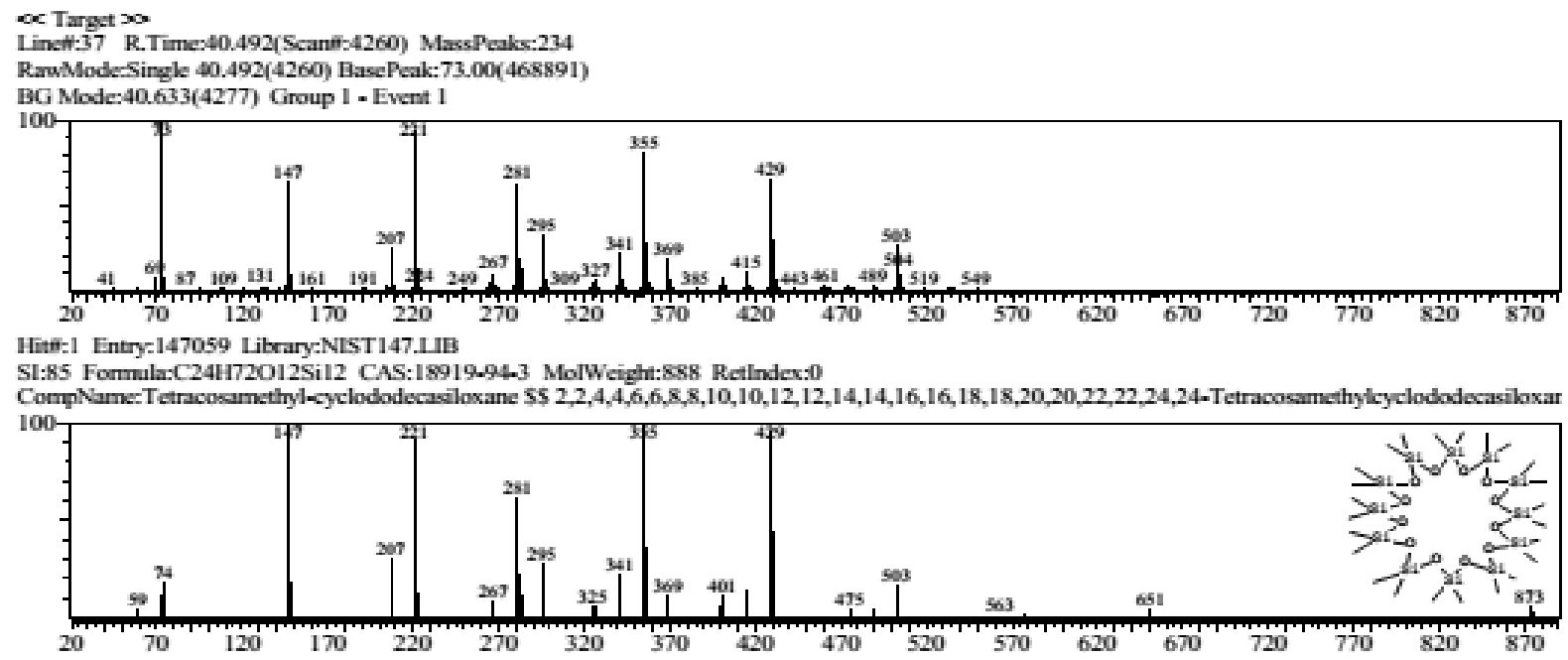

Figure 2. Fragrant aromatic compounds (phenolics) in the petroleum ether fractions of A.seyalNikhra (Tetracosamethyl-cyclododecasiloxane). 


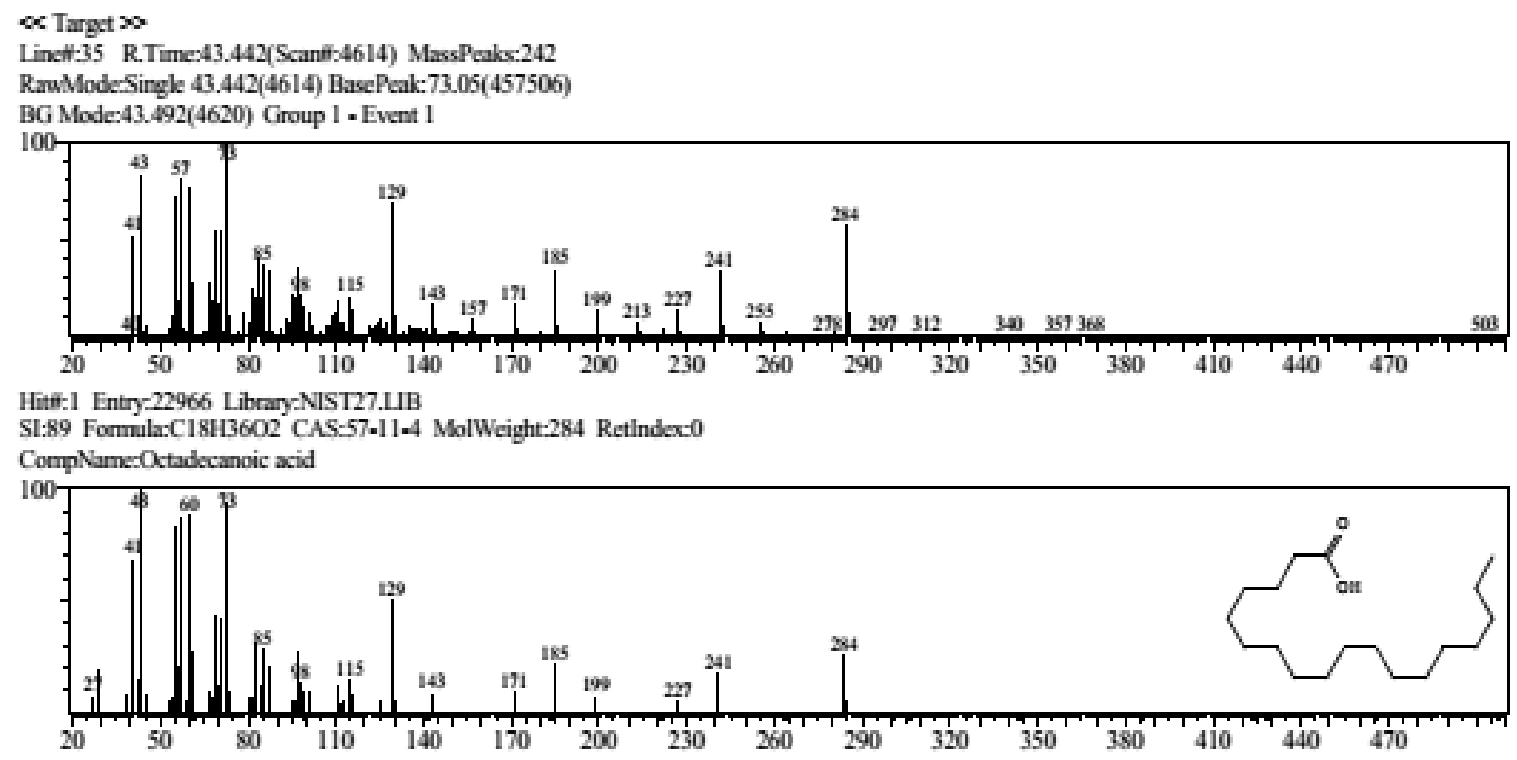

Figure 3. Fragrant aromatic compounds (terpenoids) in the petroleum ether fractions of A.seyal Nikhra(Octadecanoic acid).

\section{CONCLUSIONS}

Organoliptic survey of fragrance in different fractions of A.seyal was ensured stable and strong fragrances; these fragrances were mainly accumulated in the petroleum ether fractions. NikhraFragrance in the petroleum ether fraction which have different scents were proved to be polyphenols by TLC after spraying with NPR, specific reagent for detects components: catechin (van HCL), terponoids (van $\mathrm{H}_{2} \mathrm{SO}_{4}$ ) and lignans (van $\mathrm{H}_{3} \mathrm{PO}_{4}$ ). GC/MS analysis of the petroleum ether fraction revealed that the total fragrant compounds, phenolics and terponoids, for A. seyal was $56.44 \%$.

\section{REFERENCES}

Anjaneyulu, A. S.R. and Rao, V. L. (2000). Five diterpenoids (agallochins A \pm E) from the mangrove plant Excoecaria agallocha Linn. Phytochemistry 55: 891-901.

Balaban, M. (2004). Identification of the main phenolic compounds in wood of Ceratonia siliqua by GC-MS. Phytochem Anal.15(6):385-388.

Fyhrquist, P., Mwasumbi, L., Hæggström, C.-A., Vuorela, H., Hiltunen, R., and Vuorela, P. (2002). Ethnobotanical and antimicrobial investigation on some species of Terminalia and Combretum (Combretaceae) growing in Tanzania. Journal of Ethnopharmacology 79, 169-177.

Kimaro, A., Isaac, M., and Chamshama, S. (2011). Carbon pools in tree biomass and soils under rotational woodlot systems in Eastern Tanzania. In "Carbon Sequestration Potential of Agroforestry Systems", pp. 129-143. Springer.

Nakanishi, T., Yamagata, E., Yoneda, K., Nagashima, T., Kawasaki, I., Yoshida,T., Morii, H., Miijra, I. (1984). Three fragrant sesquiterpenes of agarwood. Phytochem. 23,(9): 2066-2067.

Orwa, C., Mutua, A., Kindt, R., Jamnadass, R., and Simons, A. (2012). Agroforestree database: a tree reference and selection guide version 4.0. Url: http://www. worldagroforestry. org/af/treedb/(Accessed on 15 February, 2011).

Wagner, H., and Bladt, S. (1996). Plant drug analysis: a thin layer chromatography atlas, Springer Science \& Business Media.

Submitted : 18.10.2018 Accepted: 30.01.2019 